\title{
Caracterizações de argilas bentoníticas e síntese de argilas organofílicas para uso em nanocompósitos poliméricos - Parte II
}

\section{(Characterization of bentonite clay and synthesis of organoclay for polymer nanocomposites applications - Part II)}

\author{
R. Barbosa' ${ }^{1}$ D. D. S. Morais $^{2}$, E. M. Araújo', T. J. A. Mélo ${ }^{2}$ \\ ${ }^{1}$ Centro de Tecnologia, Universidade Federal do Piauí, Teresina, PI 64049-550 \\ ${ }^{2}$ Depto. de Engenharia de Materiais da UFCG, Campina Grande, PB 58429-900 \\ rrenatabarbosa@yahoo.com,dayannediniz@hotmail.com, karine.nobrega@yahoo.com.br, \\ edcleide@dema.ufcg.edu.br,tomas@dema.ufcg.edu.br
}

\begin{abstract}
Resumo
Nanocompósitos poliméricos tem atraído um considerável interesse, o que se deve a estes materiais oferecerem combinações incomuns de propriedades. As argilas esmectíticas são comumente utilizadas como fase dispersa na obtenção dos nanocompósitos, em particular destaque para as argilas bentoníticas. Neste trabalho, foram estudadas três argilas bentoníticas sem modificação e após a modificação ou organofilização com o sal cloreto de estearil dimetil amônio. A capacidade de troca catiônica (CTC) das argilas bentoníticas sem modificação foi realizada. A eficiência da organofilização foi avaliada por fluorescência de raios X e o grau de expansão das argilas organofílicas foram estudados por difração de raios X. A argila 1346 apresentou maior CTC em relação às demais argilas. Além disso, os resultados indicaram a organofilização das argilas com o sal quaternário de amônio, o que foi observado pela presença do sal no espaçamento basal das argilas e pela expansão basal na reflexão $\mathrm{d}_{001}$ das argilas.

Palavras-chave: argila bentonítica, argila organofílica, nanocompósitos.
\end{abstract}

\begin{abstract}
Polymeric nanocomposites have attracted considerable interest because this material offers unusual combination of properties. The smectite clays are commonly used as the dispersed phase to obtain nanocomposites, in particular, bentonite clays. In this work three bentonite clays without modification and after modification with salt or organophilization stearyl dimethyl ammonium chloride were studied. The cation exchange capacity (CEC) of bentonite clay was carried out without modification. The efficiency of organophilization was evaluated by X-ray fluorescence and the degree of expansion of the organoclay by X-ray diffraction. The 1346 clay shows higher CEC than that of other clays. In addition, the results indicate that organophilization clays with quaternary ammonium salt, which was observed by the presence of salt in the basal spacing of clay and the expansion of the basal reflection $d_{001}$ clays.
\end{abstract}

Keywords: bentonite clay, organoclay, nanocomposites.

\section{INTRODUÇÃO}

Os nanocompósitos poliméricos reforçados com argilas são um dos materiais mais estudados na nanotecnologia [13]. Esses materiais apresentam a fase dispersa (argila) sob a forma de lamelas de aproximadamente 1,0 $\mathrm{nm}$ de espessura e centenas de nanômetros de largura e comprimento, possuindo fator de forma elevadíssimo [4]. Surgiram como alternativas adequadas para superar as limitações dos compósitos e microcompósitos, proporcionando melhoras interessantes nas propriedades desses materiais. Embora ainda representem desafios relacionados com a preparação para o controle da composição química e estequiometria na fase nanoaglomerada [5]. Dentre as argilas extensivamente empregadas como nanocargas, destacam-se as argilas bentoníticas. Bentonítica pode ser definida como uma rocha constituída essencialmente por um argilomineral montmorilonítico (esmectítico), formado pela desvitrificação e subseqüente alteração química de um material vítreo, de origem ígnea, usualmente um tufo ou cinza vulcânica [6]. Essa argila apresenta a propriedade de aumentar várias vezes o seu volume inicial na presença de umidade, com uma granulometria fina que contém um mínimo de 85,0\% do argilomineral montmorilonítico [7]. A composição química e a fórmula da cela unitária da montmorilonita "teórica" ou extremo da série é $\left(\mathrm{Al}_{3},{ }_{33} \mathrm{Mg}_{0,67}\right) \mathrm{Si}_{8} \mathrm{O}_{20}(\mathrm{OH})_{4} \cdot \mathrm{M}^{+1}{ }_{0,67}$, onde $\mathrm{M}^{+1}$ é um cátion monovalente. Essa fórmula mostra que a cela unitária tem carga elétrica negativa, devido à substituição isomórfica do $\mathrm{Al}^{3+}$ por $\mathrm{Mg}^{2+}$. $\mathrm{O}$ cátion $\mathrm{M}^{+}$que balanceia a carga negativa é chamado "cátion trocável", uma vez que pode ser trocado, de forma reversível, por outros cátions [8]. O teor do cátion trocável, expresso em 
miliequivalentes do cátion por $100 \mathrm{~g}$ de argila, é chamado CTC - capacidade de troca de cátions. A Fig. 1 ilustra o argilomineral montmorilonítico presente nas bentoníticas. $\mathrm{O}$ empilhamento das camadas é regido por forças polares relativamente fracas e por forças de Van der Waals e entre essas camadas existem lacunas denominadas galerias ou camadas intermediárias nas quais residem os cátions trocáveis como $\mathrm{Na}^{+}, \mathrm{Ca}^{2+}, \mathrm{Li}^{+}$, fixos eletrostaticamente.

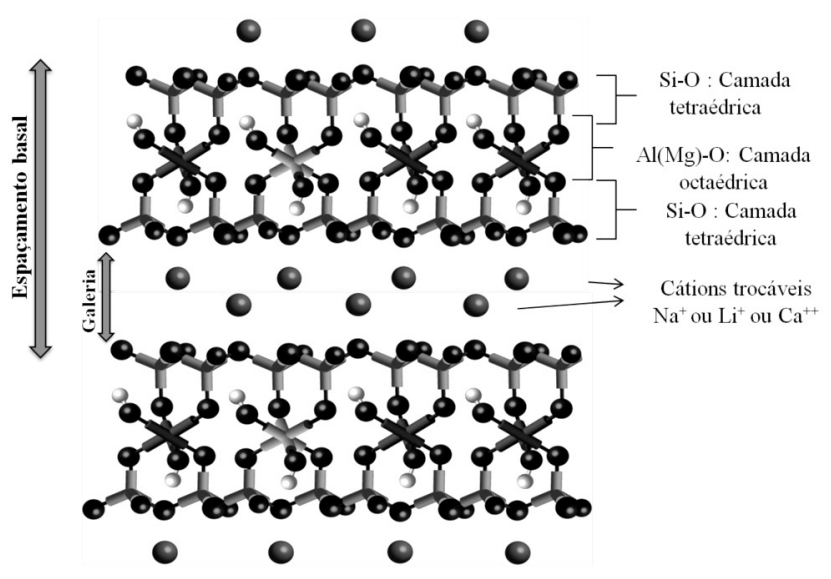

Figura 1: Representação esquemática da estrutura do argilomineral montmorilonita [9].

[Figure 1: Schematic representation of the montmorillonite mineral clay structure [9]].

O espaçamento basal das bentoníticas pode variar de 11,8 A a um máximo de $18 \AA$ em estado seco, onde as camadas sucessivas estão ligadas frouxamente entre si e camadas de água podem penetrar entre elas, separando-as e deixando-as livres, quando o espaçamento basal atinge valores superiores a $40 \AA$, caracterizando um elevado grau de delaminação [10]. Devido à habilidade de variar o espaçamento basal, seja pela intercalação de moléculas de água, seja pela contração na secagem (com a perda de moléculas de água), a montmorilonita e os demais argilominerais do grupo das esmectitas são comumente chamados de "argilominerais com distância basal expansível reversivelmente" [11].

Duas características particulares das argilas desempenham um papel importante na criação de nanocompósitos: a primeira é a capacidade de folhas de silicato de se dispersar em individuais camadas, e a segunda é a possibilidade de modificar sua superfície química por meio de reações de troca iônica com cátions orgânicos e inorgânicos. A simples mistura de polímero e argila nem sempre resulta na geração de um nanocompósito, ocasionado geralmente devido à dispersão das camadas empilhadas. Esta falha é devida às interações fracas entre o polímero e o componente inorgânico. Se estas interações se tornam mais fortes, então a fase inorgânica torna a ser dispersa na matriz orgânica em escala nanométrica [12]. Logo, a compatibilização da argila com a matriz polimérica é realizada usualmente, através da organofilização da argila por meio de reações de troca catiônica. As argilas organofílicas são frequentemente obtidas pela substituição dos cátions trocáveis presentes na galeria das argilas, geralmente $\mathrm{Na}^{+}$que é mais facilmente trocável por ser monovalente, por cátions orgânicos de sais quaternários de amônio, ou mesmo outros tipos de sais, em soluções aquosas através de reações de troca iônica $[1,13,14]$. Após a troca catiônica, as argilas apresentam a propriedade de inchar em solventes orgânicos e um caráter organofílico bastante elevado. O estudo do tipo de bentonita sódica, tipo de sal quaternário de amônio e do processo de obtenção da argila organofílica é de suma importância, uma vez que poderão definir os solventes orgânicos no qual a argila irá inchar [15].

Os objetivos deste trabalho são estudar três argilas bentoníticas ativadas sodicamente, avaliar a intercalação destas argilas com o sal cloreto de estearil dimetil amônio, e dar continuidade ao estudo realizado anteriormente [16]. O estudo destas argilas visa a sua incorporação em matrizes poliméricas na obtenção de nanocompósitos.

\section{MATERIAIS E MÉTODOS}

Foram utilizadas as argilas bentoníticas ativadas sodicamente: 1346, fornecida pela Ind. Bentonit União Nordeste (BUN), Campina Grande, PB; a AG4 e a AN3 fornecidas pela Schumacher Insumos para Ind., Porto Alegre, RS. As argilas sem modificações foram caracterizadas com a posterior organofilização com o sal cloreto de estearil dimetil amônio (Praepagen $\mathrm{WB}^{\circledR}$, PRA). O sal foi fornecido pela Clariant, Recife, PE.

Capacidade de troca de cátions (CTC): Foi determinada a capacidade de troca de cátions das argilas a partir do método de adsorção de azul de metileno [17].

Fluorescência de raios X (FRX): As análises químicas da argila sem modificação e da argila modificada (organofílica) com o sal de amônio foram realizadas por fluorescência de raios $\mathrm{X}$ pelo método semiquantitativo, em forma de pó, sob atmosfera de hélio. O equipamento utilizado foi EDX 700-Shimadzu.

Difração de raios X (DRX): As análises de DRX das argilas bentoníticas e organofílicas foram conduzidas em aparelho XRD-6000 Shimadzu, com radiação k $\alpha$ do cobre, tensão $40 \mathrm{kV}$, corrente $30 \mathrm{~mA}$, varredura entre $2 \theta$ de $1,5^{\circ}$ a $30^{\circ}$ e varredura de $2^{\circ} / \mathrm{min}$.

Síntese das argilas organofílicas: O método de síntese das argilas organofílicas e o cálculo do percentual do sal quaternário de amônio foram realizados em função da capacidade de troca de cátions da argila e do peso molecular do sal $[15,18]$. As argilas foram organofilizadas a $100 \%$ da CTC.

\section{RESULTADOS E DISCUSSÃO}

\section{Capacidade de troca de cátions (CTC)}

O resultado da CTC das argilas é um fator importante na escolha das bentoníticas a serem modificadas com o sal quaternário de amônio. A Tabela I apresenta os resultados da CTC das argilas em estudo. 
Tabela I - Capacidade de troca de cátions das bentonitas. [Table I - Cation exchange capacity of bentonites.]

\begin{tabular}{cc}
\hline ARGILA & CTC (meq/100 g de argila) \\
\hline 1346 & 90 \\
AG4 & 74 \\
AN3 & 72 \\
\hline
\end{tabular}

A argila 1346 possui o maior valor de CTC, 90 meq/100 $\mathrm{g}$ de argila. Quanto maior a CTC, maior será a troca de sódio, presente nas galerias das bentoníticas, por íons alquil amônio [19]. Este tipo de troca iônica é muito importante, visto que os íons permutáveis influenciam fortemente nas suas propriedades físico-químicas e nas suas aplicações tecnológicas [20]. Estes íons trocáveis podem ser orgânicos e/ou inorgânicos [8]. Os resultados obtidos para a CTC das argilas estão coerentes com os dados de CTC de um argilomineral esmectítico.

\section{Fluorescência de raios $X$}

A Tabela II apresenta as composições químicas determinadas por fluorescência de raios X das argilas 1346, AG4 e AN3 sem modificação e após organofilização com o sal quaternário de amônio PRA. Todas as argilas apresentam composições característica de bentoníticas.
A argila 1346 apresentou teor de ferro mais elevado do que as argilas AG4 e AN3, o que é característico das argilas do município de Boa Vista, $\mathrm{PB}$, o que provavelmente poderá contribuir para o abaixamento da temperatura de desidroxilação e diminuição da estabilidade térmica do material [21]. A argila AG4 apresenta elevado teor de magnésio quando comparado com as demais argilas. Este valor é compatível com os resultados de DRX que serão apresentados. A presença deste óxido indica que a argila AG4 foi produzida a partir de condições mineralógicas diferentes que a 1346 e AN3. De acordo com o fabricante da AG4, esta é uma montmorilonita retirada de regiões vulcânicas, rica em sais minerais silício e magnésio. Sua principal aplicação é na elaboração de tintas e vernizes por apresentar melhor comportamento reológico durante a aplicação, aumentando assim o rendimento do dispersor por ajuste da viscosidade na massa de origem, entre outras aplicações. Provavelmente foi utilizada para a produção da AG4 uma variedade mineralógica mais nobre apresentando teor mais elevado de $\mathrm{MgO}$.

A variedade mineralógica mais nobre de Boa Vista, PB, encontra-se praticamente esgotada, sendo provavelmente utilizada na produção de bentoníticas sódicas para finalidades industriais que requerem melhor comportamento reológico como para uso nos fluidos de perfuração [22].

É importante observar para as argilas sem modificação

Tabela II - Composição química das argilas sem modificação e após organofilização obtida por meio da técnica de Fluorescência de raios X.

[Table II - Chemical composition of clays without modification and after organophilization obtained by the technique of X-ray Fluorescence.]

\begin{tabular}{ccccccc}
\hline Determinações (\%) & 1346 & $1346 \mathrm{ORG}$ & $\mathrm{AG} 4$ & AG4ORG & AN3 & AN3ORG \\
\hline $\mathrm{SiO}_{2}$ & 60,75 & 61,03 & 63,43 & 66,46 & 64,24 & 66,06 \\
$\mathrm{Al}_{2} \mathrm{O}_{3}$ & 17,77 & 19,16 & 19,66 & 19,85 & 22,35 & 22,88 \\
$\mathrm{Fe}_{2} \mathrm{O}_{3}$ & $\mathbf{1 2 , 7 9}$ & 12,79 & 2,20 & 2,16 & 7,18 & 6,65 \\
$\mathrm{CaO}$ & 2,60 & 2,12 & 6,49 & 5,14 & 2,37 & 1,33 \\
$\mathrm{MgO}$ & 2,10 & 1,91 & $\mathbf{4 , 9 9}$ & 4,30 & 0,65 & 0,51 \\
$\mathrm{TiO}$ & 1,31 & 1,42 & 0,35 & 0,33 & 0,61 & 0,61 \\
$\mathrm{Na}_{2} \mathrm{O}$ & $\mathbf{1 , 1 4}$ & --- & $\mathbf{1 , 3 4}$ & --- & $\mathbf{1 , 1 9}$ & --- \\
$\mathrm{K}_{2} \mathrm{O}$ & 0,84 & 0,72 & 0,90 & 0,81 & 0,78 & 0,68 \\
$\mathrm{Cl}$ & $\mathbf{0 , 2 2}$ & $\mathbf{0 , 4 4}$ & $\mathbf{0 , 3 3}$ & $\mathbf{0 , 8 1}$ & $\mathbf{0 , 1 8}$ & $\mathbf{0 , 9 3}$ \\
$\mathrm{SO}_{3}$ & 0,12 & 0,12 & 0,07 & & 0,18 & 0,08 \\
$\mathrm{MnO}$ & 0,07 & 0,07 & 0,05 & & 0,08 & 0,08 \\
$\mathrm{Cr}_{2} \mathrm{O}_{3}$ & 0,07 & 0,08 & 0,06 & & & \\
$\mathrm{P}_{2} \mathrm{O}_{5}$ & 0,06 & & & & & 0,05 \\
$\mathrm{CuO}$ & 0,05 & 0,07 & 0,03 & 0,04 & 0,04 & 0,03 \\
$\mathrm{ZnO}$ & 0,04 & 0,04 & 0,02 & 0,02 & 0,02 & 0,03 \\
$\mathrm{SrO}_{\mathrm{ZrO}}$ & 0,04 & 0,03 & 0,04 & 0,03 & 0,03 & 0,02 \\
$\mathrm{NiO}$ & 0,03 & 0,02 & 0,03 & 0,03 & 0,07 & 0,06 \\
$\mathrm{Y}_{2} \mathrm{O}_{3}$ & 0,02 & & 0,03 & 0,03 & & \\
\hline
\end{tabular}


a presença do sódio $\left(\mathrm{Na}_{2} \mathrm{O}\right)$ e após organofilização a sua inexistência. Este dado indica que houve uma troca eficiente dos cátions sódio da bentonítica pelos cátions do cloro e também pelo aumento do percentual de $\mathrm{Cl}$ após organofilização para todas as argilas estudadas, demonstrando a presença do cátion quaternário de amônio nos espaços interlamelares da argila.

\section{Difração de raios $X$}

Os resultados de DRX das argilas 1346, AG4 e AN3 sem modificação e após a organofilização 1346ORG, AG4ORG e AN3ORG com o sal quaternário de amônio PRA estão apresentados na Fig. 2, para o percentual de $100 \%$ da CTC da argila. Observa-se para as argilas não modificadas 1346, AG4 e AN3, espaçamentos basais na reflexão $\mathrm{d}_{001}$ de 13,30 $\AA$, $14,57 \AA$ e $14,33 \AA$, respectivamente, que são característicos do grupo das esmectitas, presente nas bentoníticas.

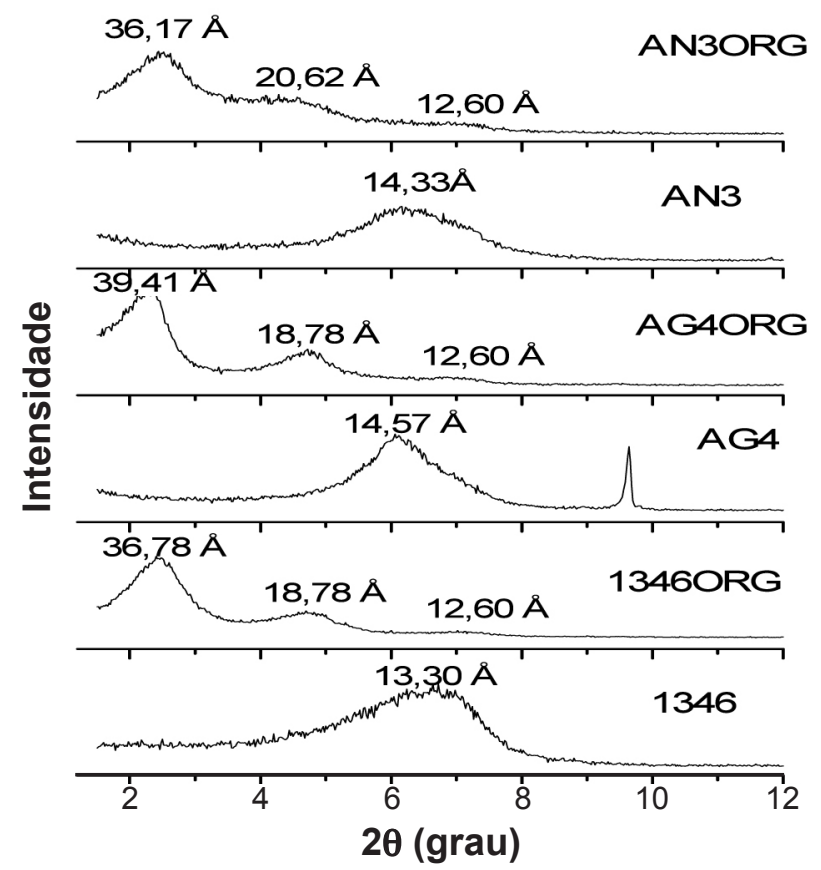

Figura 2: Difratogramas de raios X das argilas 1346, AG4 e AN3 sem modificação e após organofilização na proporção de $100 \%$ da CTC da argila.

[Figure 2: X-ray diffraction patterns of 1346, AG4 and AN3 clay without modification and after organophilization with percentage of PRA salt in the proportions of $100 \%$ of CEC of the clay.]

É interessante observar para a argila AG4 a presença de um pico intenso aproximadamente em $2 \theta=10^{\circ}$ que corresponde ao $\mathrm{MgO}$, concordando com os resultados de análise química determinados por fluorescência de raios $\mathrm{X}$ que representou quase $5 \%$ da presença desse óxido. A argila AG4 é uma montmorilonita retirada de regiões vulcânicas rica em sais minerais de silício e magnésio. A concentração de determinados minerais em qualquer montmorilonita confere-lhe qualidades especiais em várias aplicações.
Após modificações, a argila 1346ORG apresentou espaçamentos basais de 12,60 $\AA$, possivelmente devido a alguma quantidade de argila não intercalada e as distâncias de $36,78 \AA$ e $18,78 \AA$, correspondentes às reflexões basais $d_{001}$ e $d_{002}$ respectivamente [23]. A argila AG4ORG apresentou espaçamentos basais de 12,60 $\AA$, devido a alguma quantidade de argila não intercalada e as distâncias $39,41 \AA$ e $18,78 \AA$, correspondentes às reflexões basais $\mathrm{d}_{001}$ e $\mathrm{d}_{002}$, respectivamente. E a argila AN3ORG apresentou o mesmo comportamento que as demais com espaçamentos basais de 12,60 $\AA$, possivelmente a alguma quantidade de argila não intercalada e as distâncias $36,17 \AA$ e $20,62 \AA$, correspondentes provavelmente às reflexões basais $\mathrm{d}_{001} \mathrm{e}$ $\mathrm{d}_{002}$, respectivamente. Algumas explicações são possíveis para essas reflexões basais. Segundo Jordan [24], até certo número de átomos de carbono presente no sal quaternário de amônio irá ocorrer contração de reflexão basal para um valor constante, que provavelmente seria o carbono $\mathrm{C} 16$ presente na constituição do sal PRA e a partir de um valor superior ao número de carbonos, a reflexão basal aumenta para um valor constante, possivelmente referente ao carbono $\mathrm{C} 18$. A composição química e o tamanho da cadeia determinam, portanto, a distância interplanar basal da argila organofílica, bem como controlam um conjunto amplo de propriedades, especialmente adsortivas e coloidais, que levam ao seu grande uso industrial atual. Outra explicação seria que o aparecimento de vários espaçamentos basais durante a intercalação parece está associado a não uniformidade da distribuição dos íons de sódio entre as camadas do argilomineral esmectítico e a troca seletiva do sódio pelo cátion do sal [25]. Isto provocaria a formação de arranjos diferentes do sal ao longo da superfície do material, com suas moléculas formando camadas laterais, simples ou duplas em algumas regiões, e arranjos estendidos parafínicos, em camada simples ou dupla.

Todos os resultados indicam a intercalação dos íons de amônio do sal estudado dentro das camadas de silicato e expansão do espaçamento basal na reflexão $\mathrm{d}_{001}$, isto é, as argilas em estudo apresentaram deslocamentos do ângulo de $2 \theta$ para ângulos menores, indicando que a argila foi organofilizada.

\section{CONCLUSÕES}

Argilas bentoníticas foram organofilizadas com um sal quaternário de amônio por meio de reações de troca catiônica. A capacidade de troca catiônica das argilas sem modificação foi determinada, a argila 1346 apresentou maior CTC em relação às demais argilas. Por meio da técnica de fluorescência de raios $X$ foi observada a indicação da incorporação das moléculas do sal quaternário de amônio no espaçamento basal das argilas. Os resultados de difração de raios $\mathrm{X}$ indicaram a intercalação dos íons de amônio do sal estudado dentro das camadas de silicato das argilas, ocasionando com isso a expansão do espaçamento basal na reflexão $\mathrm{d}_{001}$. As argilas estudadas apresentam potencial para a obtenção de nanocompósitos poliméricos. 


\section{AGRADECIMENTOS}

Os autores agradecem à Clariant, à Bentonit União Nordeste (BUN), à Schumacher Insumos para Indústria, ao Laboratório de Engenharia de Materiais, CCT, UFCG (LabMat), à Rede de Nanotecnologia Molecular e Interfaces (RENAMI), ao MCT/CNPq e à CAPES/PROCAD-NF.

\section{REFERÊNCIAS}

[1] A. Usuki, M. Kawasumi, Y. Kojima, A. Okada, T. Kurauchi, O. Kamigaito, J. Mater. Res. 8 (1993) 1174.

[2] S. S. Ray, M. Okamoto, Prog. Polym. Sci. 28 (2003) 1539.

[3] D. R. Paul, L. M. Robeson, Polym. J. 49 (2008) 3187.

[4] P. B. Messersmith, E. P. Giannelis, Chem. Mater. 6, 10 (1994) 1719.

[5] P. H. C. Camargo, K. G. Satyanarayana, F. Wypych, J. Mater. Res. 12, 1 (2009) 1.

[6] C. S. Ross, E. V. Shannon, J. Am. Ceram. Soc. 9 (1926) 77.

[7] H. C. H. Darley, G. R. Gray, Composition and Properties of Drilling and Completion Fluids, $1^{\text {st }}$ Ed., Gulf Publ. Co., Houston, Texas, EUA (1988).

[8] P. S. Santos, Ciência e Tecnologia de Argilas, Ed. Edgard Blucher Ltda., 1ª Ed., S. Paulo, SP, Brasil (1989).

[9] L. B. Paiva, A. R. Morales, F. R. Valenzuela-Díaz, Cerâmica 54, 330 (2008) 213.

[10] F. R. Valenzuela-Díaz, P. S. Santos, H. S. Santos, Quim. Ind. 42 (1992) 33.

[11] P. S. Santos, Ciência e Tecnologia de Argilas, Edgard
Blucher Ltda., 2a Ed., S. Paulo, SP, Brasil (1992).

[12] G. Choudalakis, A. D. Gotsis, Eur. Polym. J. 45 (2009) 967.

[13] G. Lagaly, Solid State Ionics 22 (1986) 43.

[14] A. C. V. Coelho, P. S. Santos, H. S. Santos, Quim. Nova 30, 5 (2007) 1282.

[15] F. R. Valenzuela-Díaz, Preparação a nível de laboratório de algumas argilas esmectíticas organofilicas, Tese Dr. Eng. Quim., Escola Politécnica da Universidade de S. Paulo, S. Paulo, SP, Brasil (1994) 256 p.

[16] R. Barbosa, D. D. Souza, E. M. Araújo, T. J. A. Mélo, Cerâmica 56, 340 (2010) 376.

[17] H. C. Ferreira, T. Chen, A. R. Zandonadi, P. Souza Santos, Cerâmica 18, 71 (1972) 333.

[18] R. Barbosa, Estudo da modificação de Argilas Bentoníticas para Aplicação em Nanocompósitos de Polietileno, Tese Dr. Eng. Proc., Universidade Federal de Campina Grande, PB, Brasil (2009) 157 p.

[19] J. W. Cho, D. R. Paul, Polym. J. 42 (2000) 1083.

[20] I. E. Odom, Phil. Trans. Royal Soc. London 311 (1984) 391.

[21] S. Q. M. Leite, C. H. A. Colodete, L. C. Dieguez, R. A. S. San Gil, Quím. Nova 23 (2000) 297.

[22] L. V. Amorim, E. Pereira, ABAS Informa 147 (2003) 16.

[23] E. M. Araújo, R. Barbosa, A. D. Oliveira, C. R. S. Morais, A. G. Souza, T. J. A. Mélo, J. Therm. Anal. Cal. 87 (2007) 811.

[24] J. W. Jordan, J. Phys. Chem. 53 (1949) 294.

[25] S. Y. Lee, S. J. Kim, J. Colloid Interface Sci. 248 (2002) 231.

(Rec. 31/08/2011, Ac. 29/10/2011) 